\title{
ANALISIS PENDAPATAN DAN KELAYAKAN USAHATANI PADI SAWAH PASANG SURUT DI DESA CEMARA LABAT KECAMATAN KAPUAS KUALA KABUPATEN KAPUAS
}

\author{
Analysis of income and feasibility farming rice field in Cemara Labat Village Kapuas Kuala \\ District Kapuas Regency
}

\author{
Rajudinnor $^{1)}$
}

\section{1) Dosen Program Studi Agribisnis Fakultas Pertanian Universitas Palangka Raya Email : rajudinnor@gmail.com}

\begin{abstract}
Agricultural development is basically one of the systems development is no less important in supporting the success of national development. Development of the agricultural sector aims to develop agricultural businesses in rural areas that will spur rural economic activity, create jobs and improve the welfare of society grow upstream, downstream and support in enhancing the competitiveness and added value of agricultural products. The purpose of this study to: (i) large knowing rice farming income in Cemara Labat Village Kapuas Kuala District Kapuas regency, (ii) determine the feasibility of rice farming In Cemara Labat Village Kapuas Kuala District Kapuas regency. Determination of respondent committed intentionally (purposive), Total farmer respondents (sample) taken in this study of 30 rice farmers. The analysis used in this penelitiaan is revenue analysis and feasibility analysis. The results showed that rice farming income in the village of Cemara Labat Kapuas Kuala District of Rp 10.807.462 $\mathrm{Ha}^{-1}$. Rice farm In Cemara Labat Village Kapuas Kuala District Kapuas regency viable with the value of revenue cost ratio (RCR ) to 2.73 , which means that any expenditure of Rp 1.000,- will generate revenue of Rp 2.730,--
\end{abstract}

Key words: Income, Feasibility, Rice Fields

\begin{abstract}
ABSTRAK
Pembangunan pertanian pada dasarnya merupakan salah satu sistem pembangunan yang tidak kalah pentingnya dalam mendukung keberhasilan pembangunan nasional. Pembangunan sektor pertanian bertujuan untuk menumbuh kembangkan usaha pertanian di pedesaan yang akan memacu aktivitas ekonomi pedesaan, menciptakan lapangan pekerjaan dan meningkatkan kesejahteraan masyarakat menumbuhkan industri hulu, hilir dan penunjang dalam meningkatkan daya saing dan nilai tambah suatu produk pertanian. Tujuan penelitian ini untuk : (i) mengetahui besar pendapatan usahatani padi sawah pasang surut di Desa Cemara Labat Kecamatan Kuala Kapuas Kabupaten Kapuas (ii) mengetahui kelayakan usahatani padi sawah di Desa Cemara Labat Kecamatan Kapuas Kuala Kabupaten Kapuas. Penentuan responden dilakukan dengan sengaja (purposive), Jumlah petani responden (sampel) yang diambil dalam penelitian ini sebanyak 30 petani padi sawah. Analisis yang digunakan dalam penelitiaan ini adalah analisis pendapatan dan analisisis kelayakan. Hasil penelitian menunjukan bahwa Pendapatan usahatani padi sawah pasang surut di Desa Cemara Labat Kecamatan Kapuas Kuala sebesar Rp 10.807.462 per Hektar. Usahatani padi sawah pasang surut di Desa Cemara Labat Kecamatan Kapuas Kuala Kabupaten Kapuas layak diusahakan dengan nilai RCR 2,73 yang artinya bahwa setiap pengeluaran sebesar Rp 1.000,- akan menghasilkan penerimaan Rp 2.730,-.
\end{abstract}

Kata Kunci : Pendapatan, Kelayakan, Padi Sawah

\section{PENDAHULUAN}

\section{Latar belakang}

Pembangunan pertanian pada dasarnya adalah salah satu sistem pembangunan yang tidak kalah pentingnya dalam mendukung keberhasilan pembangunan nasional. Pembangunan sektor pertanian bertujuan untuk menumbuh kembang kan usaha pertanian di 
pedesaan yang akan memacu aktivitas ekonomi pedesaan, menciptakan lapangan pekerjaan dan peningkatan kesejahteraan masyarakat menumbuh kan industri hulu, hilir dan penunjang dalam meningkatkan daya saing dan nilai tambah suatu produk pertanian, memanfaatkan sumberdaya pertanian secara optimal melalui pemanfaatan teknologi yang tepat (Maria, 2016).

Pengembangantanaman pangan merupakan salah satu bagian dari sektor pertanian yang mendapat perhatian serius dan terus dikembang kan sampai saat ini. Tujuan pembangunan pangan adalah untuk mewujudkan kondisi terpenuhinya kebutuhan pangan dengan gizi yang cukup bagi penduduk untuk menjalani hidup yang sehat dan produktif. Bertambahnya jumlah penduduk dan perubahan selera makan maka ketersediaan pangan harus ditingkatkan baik dalam jumlah, kualitas maupun keragamannya.

Padi dipilih oleh petani sebagai salah satu komoditi yang diusahakan karena peranannya sebagai salah satu makanan pokok yang makin hari terasa penting karena mengandung nilai gizi dan energi yang cukup bagi tubuh manusia, dapat menciptakan lapangan pekerjaan serta dapat meningkatkan pendapatan petani.

Di wilayah Kalimantan Tengah permintaan masyarakat akan produksi padi sawah berupa beras terus meningkat. Hal ini seiring dengan jumlah penduduk yang terus meningkat dan oleh kebiasaan sebagian masyarakat yang mengkonsumsi nasi dan tidak dapat digantikan oleh bahan makanan lain. Demi memenuhi permintaan tersebut, maka dibutuhkan program peningkatan produksi baik melalui pemanfaatan lahan sebaikbaiknya dengan penggunaan teknologi secara tepat maupun melalui perluasan lahan untuk mendapatkan produksi yang maksimal.

Produksi padi sawah di Kalimantan Tengah mengalami fluktuasi, pada tahun 2015 luas panen sebesar 186.509 ha, dengan produksi sebanyak 709.357 ton GKG. Sedangkan pada tahun 2016 luas panen turun menjadi 183.416 ha, namun produksi meningkat menjadi 725.755 ton GKG. (BPS, 2017).

Kabupaten Kapuas merupakan sentra penghasil padi sawah di wilayah Kalimantan Tengah dengan luas panen pada tahun 2016 sebesar 11.073 ha dan produksi sebesar 44.777 ton. Berdasarkan data luas panen, dan produksi padi sawah di Kecamatan Kapuas Kuala menunjukkan bahwa Desa Cemara Labat merupakan Desa penghasil padi sawah terbesar dengan luas panen 1.116 ha dan produksi sebesar 4.513 ton pada tingkat produktivitas 4,044 ton/ha (Dinas Pertanian Kab Kapuas, 2017).

Desa Cemara Labat dengan luas wilayah $35,1 \mathrm{~km} 2$ dan dengan jumlah penduduk 1.269 jiwa merupakan daerah yang berpotensi sebagai salah satu penghasil tanaman pangan khususnya padi sawah pasang surut. Tingkat produktivitas padi yang tinggi di desa Cemara Labat diharapkan dapat memberikan kontribusi pada pendapatan keluarga petani padi sawah pasang surut di desa tersebut.

Secara umum peningkatan produksi suatu usahatani merupakan salah satu indikator keberhasilan dari usahatani yang bersangkutan. Namun demikian tingginya produksi suatu komoditas yang diperoleh per satuan luas lahan belum menjamin tingginya pendapatan usahatani padi sawah yang dipengaruhi oleh harga yang diterima oleh petani dan biaya- biaya penggunaan input usahatani. Besarnya produksi belum menjamin pula besarnya tingkat pendapatan. Dalam hubungan tersebut maka perlu diadakan penelitian mengenai analisis pendapatan dan kelayakan usahatani padi sawah di Desa Cemara Labat Kecamatan Kapuas Kuala Kabupaten Kapuas.

\section{Tujuan penelitian}

Tujuan penelitian ini sebagai berikut: 
1. Mengetahui besar pendapatan usahatani padi sawah pasang surut di Desa Cemara Labat Kecamatan Kuala Kapuas Kabupaten Kapuas.

2. Mengetahui kelayakan usahatani padi sawah pasang surut di Desa Cemara Labat Kecamatan Kapuas Kuala Kabupaten Kapuas.

\section{METODE PENELITIAN}

Tempat dan waktu. Penelitian ini dilaksanakan di Desa Cemara Labat, Kecamatan Kapuas Kuala Kabupaten Kapuas. Lokasi penelitian ditentukan secara sengaja (Purposive), dengan pertimbangan bahwa desa Cemara Labat adalah sentra padi di kecamatan Kapuas Kuala. Desa Cemara Labat adalah daerah penghasil padi sawah pasang surut terbanyak di Kecamatan Kapuas Kuala. Penelitian dilaksanakan mulai Bulan Maret sampai Mei 2017.

Pengumpulan Data. Data yang dikumpulkan dalam penelitian ini berasal data primer dan data sekunder. Data primer diambil dengan cara observasi dan wawancara kepada petani responden dengan menggunakan daftar pertanyaan atau Questionaire. Data sekunder yaitu data yang diperoleh dari literatur serta berbagai instansi terkait.

Penentuan responden. Penentuan responden dilakukan dengan metode sampel acak sederhana (simple Random sampling), dengan pertimbangan jumlah responden yang diambil dalam penelitian sebesar 30 orang (12\%) dari populasi petani padi sawah pasang surut di desa Cemara Labat sebesar 250 petani.

Analisis data. Metode analisis data yang digunakan dalam penelitian ini adalah analisis pendapatan dan kelayakan. Analisis pendapatan usahatani digunakan untuk mengetahui berapa besar pendapatan usahatani padi sawah, sedangkan analisis kelayakan digunakan untuk mengetahui usahatani layak diusahakan, sebagai berikut :
Analisis pendapatan. Soekartawi (1995), menyatakan pendapatan usahatani adalah selisih antara penerimaan dan semua biaya, dimana penerimaan usahatani dalah perkalian antara produksi dan harga jual, sedangkan biaya adalah semua pengeluaran yang digunakan dalam suatu usahatani. Persamaan tersebut dituliskan sebagai berikut :

$$
\mathbf{I}=\mathbf{T R}-\mathbf{T C}
$$

Keteragan :

$$
\begin{array}{ll}
\mathrm{I} & =\text { Income }(\text { Pendapatan) }(\mathrm{Rp}) \\
\mathrm{TR} & =\text { Total Penerimaan }(\mathrm{Rp}) \\
\mathrm{TC} & =\text { Total Biaya }(\mathrm{Rp})
\end{array}
$$

Total biaya dapat dihitung dengan menggunakan rumus sebagai berikut :

$$
\mathbf{T C}=\mathbf{F C}+\mathrm{VC}
$$

Keterangan :

$$
\begin{aligned}
& \mathrm{TC}=\text { Total Biaya (Rp) } \\
& \mathrm{FC} \quad=\text { Biaya Tetap (Rp) } \\
& \mathrm{VC}=\text { Biaya Variabel }(\mathrm{Rp}) \\
& \text { berikut : } \\
& \mathbf{T R}=\mathbf{Q} \cdot \mathbf{P} \\
& \mathrm{TR}=\text { Total Penerimaan }(\mathrm{Rp}) \\
& \mathrm{Q}=\operatorname{Jumlah} \operatorname{Produk}(\mathrm{Kg}) \\
& \mathrm{P} \quad=\text { Harga Produk }(\mathrm{Rp})
\end{aligned}
$$$$
\text { Penerimaan dapat dihitung }
$$$$
\text { dengan menggunakan rumus sebagai }
$$

Analisis kelayakan. Analisis yang digunakan untuk menjawab masalah butir kedua yaitu analisis kelayakan. Analisis kelayakan digunakan untuk mengetahui apakah usahatani yang dilakukan oleh petani layak atau tidak layak ataupun impas. Soekartawi (1995), Analisis R/C yang dikenal dengan perbandingan antara total penerimaan dan total biaya, dengan menggunakan rumus sebagai berikut :

$$
\mathbf{R C R}=\mathbf{T R} / \mathbf{T C}
$$

$\mathrm{RCR}=$ Perbandingan antara Penerimaan dengan biaya 
$\mathrm{TR}=$ Total Penerimaan $(\mathrm{Rp})$

$\mathrm{TC}=$ Total Biaya $(\mathrm{Rp})$

\section{Dengan kriteria :}

Jika RCR > 1, maka usahatani layak

Jika RCR $<1$, maka usahatani tidak layak untuk diusahakan

Jika RCR = 1, maka usahatani tidak untung dan tidak rugi.

\section{HASIL DAN PEMBAHASAN}

Karakteristik Responden. Petani padi sawah pasang surut di Desa Cemara Labatmemiliki karakteristik yang berbeda. Karakteristik petani responden merupakan ciri-ciri yang dimiliki oleh setiap responden yang berhubungan dengan usahatani yang dikelolanya, meliputi umur, tingkat pendidikan, jumlah tanggungan keluarga dan pengalaman berusahatani.

Umur. Rata-rata umur petani responden padi sawah di Desa Cemara Labat, rata-rata berusia 48 tahun. Hal ini menunjukkan kisaran umur petani dalam usia produktif 15-64 tahun (BPS, 2016).

Tingkat Pendidikan.Tingkat pendidik an menentukan kemampuan dalam menerima inovasi dan teknologi baru, sehingga mempengaruhi petani dalam melaksanakan kegiatan produksi. Adapun pendidikan tersebut terdiri dari pendidikan formal melalui jenjang pendidikan dan non formal diperoleh melalui pelatihan yang dapat berguna bagi kepentingan dan pengembangan usahataninya. Sebagian besar $65 \%$ petani di Desa Cemara Labat Kecamatan Kapuas Kuala tingkat pendidikan SD. Rendahnya tingkat pendidikan ini mempengaruhi petani dalam menerima informasi dan mengadopsi teknologi.

Jumlah Tanggungan Keluarga. Jumlah tanggungan tiap kepala keluarga ditentukan oleh banyaknya anggota keluarga yang menjadi tanggung jawab dari seorang kepala keluarga. Semakin banyak jumlah anggota keluarga berarti semakin besar pula jumlah tenaga kerja yang tersedia dalam pengolahan usahanya, namun banyaknya jumlah anggota keluarga juga berakibat semakin besar pula biaya kebutuhan hidup yang harus dikeluarkan, sehingga berpengaruh terhadap pendapatan yang diperoleh. Rata-rata tanggungan keluarga responden sebanyak 4 orang. Hal ini menyebabkan petani memiliki beban tanggungan untuk menyediakan segala kebutuhan keluarganya.

Pengalaman Berusahatani. Pengalam an berusahatani dinyatakan dalam jangka waktu seorang petani melakukan kegiatan usahataninya. Pengalaman tersebut memungkinkan petani melakukan perbaikan atas kesalahan yang telah dilakukan sebelumnya dan akan lebih berhati-hati dalam bertindak guna meningkatkan pendapatan. Rata-rata pengalaman berusahatani petani responden selama 26 tahun. Petani responden telah memiliki banyak pengalaman dalam mengelola usahataninya. Pengalaman yang dimiliki petani dapat berdampak terhadap adopsi petani akan inovasi baru. Pengalaman dalam berusahatani merupakan faktor yang dapat menunjang petani dalam meningkatkan kemampuan kerjanya dalam berusahatani.

\section{Analisis Pendapatan Usahatani Padi} Sawah. Analisis pendapatan dalam penelitian ini digunakan untuk mengetahui besarnya pendapatan petani responden pada usahatani padi sawah di Desa Cemara Labat kecamatan Kapuas Kuala kabupaten Kapuas selama satu kali musim tanam, dengan cara menghitung selisih antara total penerimaan dan total biaya yang digunakan dalam berusahatani.

Analisis Kelayakan Usahatani Padi Sawah. Analisis kelayakan digunakan untuk mengetahui apakah usahatani yang 
dilakukan oleh petani layak atau tidak layak ataupun impas. Soekartawi (1995), Analisis RCR yang dikenal dengan perbandingan antara total penerimaan dan total biaya.

Tabel 1. Analisis Pendapatan Usahatani Padi Sawah di Desa Cemara Labat Kecamatan Kapuas Kuala Kabupaten Kapuas, 2017

\begin{tabular}{|c|c|c|c|}
\hline No. & Uraian & $\begin{array}{l}\text { Nilai Aktual } \\
\text { (Rp/ 0,96 Ha) }\end{array}$ & $\begin{array}{c}\text { Nilai } \\
\text { Konversi } \\
(\mathbf{R p} / \mathbf{1 , 0 0 ~ H a )} \\
\end{array}$ \\
\hline \multirow[t]{4}{*}{1.} & Penerimaan Usahatani & & \\
\hline & - Rata-rata produksi $(\mathrm{Kg} / \mathrm{Ha})$ & 2.952 & 3.080 \\
\hline & - Harga Jual GKG $(\mathrm{Rp} / \mathrm{Kg})$ & 5.400 & 5.400 \\
\hline & Rata-Rata Penerimaan & 15.940 .800 & 16.632.000 \\
\hline \multirow[t]{12}{*}{2.} & Biaya Produksi (Rp/Ha) & & \\
\hline & a. Total Biaya Tetap & 267.944 & 279.594 \\
\hline & - Pajak Lahan & 14.300 & 14.922 \\
\hline & - Penyusutan Alat & 253.644 & 264.672 \\
\hline & b. Total Biaya Variabel & 5.581 .849 & 5.824 .538 \\
\hline & - Upah Tenaga Kerja & 3.450 .960 & 3.601 .003 \\
\hline & - Benih & 140.760 & 146.880 \\
\hline & - Pupuk & 743.060 & 775.367 \\
\hline & - $\quad$ Roundup $480 \mathrm{~g} / \mathrm{l}$ dan Insektisida & 652.621 & 680.994 \\
\hline & Rata-Rata Biaya Total & 5.849 .793 & 6.104.132 \\
\hline & Rata-Rata Pendapatan (1-2) & 10.358 .951 & 10.807 .462 \\
\hline & Revenue Cost Ratio ( 2/1) & 2,73 & 2,73 \\
\hline
\end{tabular}

Sumber : Hasil Analisis Data Primer, 2017

Tabel 1 menunjukkan bahwa ratarata luas lahan $0,96 \mathrm{Ha}$, rata-rata produksi $2.952 \mathrm{Kg} / 0,96 \mathrm{Ha}$ atau setara dengan konversi $3.080 \mathrm{Kg} / \mathrm{Ha}$ dan harga jual Rp $5.400 / \mathrm{Kg} \mathrm{GKG}$, jadi ratarata penerimaan petani sebesar $\mathrm{Rp}$ 15.940.800/ Ha atau setara dengan konversi Rp 16.632.000 / Ha. Sedangkan rata- rata biaya tetap sebesar $\mathrm{Rp} 267.944$ /0,96 Ha atau setara dengan konversi $\mathrm{Rp}$ $279.594 / \mathrm{Ha}$ dan total biaya variabel $\mathrm{Rp}$ /0,96 Ha atau setara dengan konversi $\mathrm{Rp}$ 3.235.854/Ha. Jadi rata-rata total biaya produksi sebesar Rp 5.849.793/0,96 Ha atau setara dengan konversi Rp 6.104.132 /Ha. Setelah dilakukan pengurangan antara rata-rata penerimaan dan rata-rata biaya total, diketahui bahwa rata- rata pendapatan yang diperoleh petani padi sawah di Desa Cemara Labat Kecamatan Kapuas Kuala Kabupaten

\section{KESIMPULAN DAN SARAN}

\section{Kesimpulan}

Dari hasil penelitian ini diperoleh kesimpulan sebagai berikut :

1. Pendapatan usahatani padi sawah pasang surut di Desa Cemara Labat Kecamatan Kapuas Kuala Kabupaten Kapuas sebesar Rp 10.807.462 per Ha.

2. Berdasarkan hasil perhitungan kelayakan usahatani, diketahui bahwa usahatani padi sawah pasang surut di Desa Cemara Labat Kecamatan Kapuas Kuala Kabupaten Kapuas layak diusahakan dengan nilai RCR sebesar 2,73 atau RCR > 1, yang artinya bahwa setiap pengeluaran sebesar Rp 1.000 akan menghasilkan penerimaan sebesar Rp 2.730. 
Kapuas sebesar Rp 10.358.951 /0,96 Ha atau setara dengan konversi Rp 10.807.462 per Ha.

Analisis Kelayakan Usahatani Padi Sawah. Hasil penelitian yang telah dilakukan diperoleh tingkat kelayakan usahatani padi sawah di Desa Cemara Labat sebagai berikut :

$$
\begin{aligned}
& \mathrm{RCR}=\mathrm{TR} / \mathrm{TC} \\
& \mathrm{RCR}=\mathrm{Rp} 16.632 .000 / \mathrm{Rp} 6.104 .132 \\
& \mathrm{RCR}=2.73
\end{aligned}
$$

Hal ini berarti setiap pengeluaran sebesar Rp 1.000 akan menghasilkan penerimaan sebesar Rp 2.730 .

Hasil analisis menunjukkan bahwa usahatani padi sawah pasang surut di Desa Cemara Labat Kecamatan Kapuas Kuala Kabupaten Kapuas layak diusahakan. Hal ini dibuktikan dengan nilai RCR > 1.

\section{Saran}

Dalam upaya peningkatan produksi padi sawah hendaknya penyuluh pertanian lebih berperan aktif dalam memberikan informasi kepada petani mengenai penggunaan input produksi agar lebih efektif guna memperoleh produksi yang tinggi sehingga pendapatan petani lebih meningkat.

\section{DAFTAR PUSTAKA}

BPS. 2017. Kalimantan Tengah Dalam Angka 2016. Badan Pusat Statistik Provinsi Kalimantan Tengah. Palangka Raya.

BPS. 2017. Kabupaten Kapuas Dalam Angka 2016. Badan Pusat Statistik Kabupaten Kapuas.

Soekartawi. 1995. Analisis Usahatani. UI Press. Jakarta.
Susanto, Hery. 2010. Analisis Pendapatan dan Kelayakan Usahatani Padi Sawah di Desa Karawana Kecamatan Dolo Kabupaten Sigi Jurnal Agrotekbis 2 (3) : 332-336, Juni 2014. 